\title{
Passivation and Depassivation of HPB335 Carbon Steel in Simulated Concrete Pore Solution
}

\author{
Haodong Ji ${ }^{1}$, Ye Tian ${ }^{1, *}$, Ruoyi Zhao ${ }^{2}$, Nanguo Jin ${ }^{1}$, Xianyu Jin ${ }^{1}$, Zushi Tian ${ }^{1,3}$, Dongming Yan ${ }^{1}$, \\ Hailong $Y e^{3}$ \\ ${ }^{1}$ College of Civil Engineering and Architecture, Zhejiang University, Hangzhou 310058, P.R. China; \\ ${ }^{2}$ Department of Art Design, Zhejiang Gongshang University, Hangzhou 310058, P.R. China; \\ ${ }^{3}$ Department of Civil Engineering, The University of Hong Kong, Pokfulam, Hong Kong 999077, \\ P.R. China; \\ "E-mail: cetianye@zju.edu.cn
}

doi: $10.20964 / 2020.07 .43$

Received: 22 February 2020 / Accepted: 9 April 2020 / Published: 10 June 2020

\begin{abstract}
In order to study the corrosion mechanism of carbon steel, the passive film characteristics, critical chloride threshold and depassivation of HPB335 carbon steel in different solutions were studied. This study mainly used Mott-Schottky analysis, open-circuit potential, linear polarization resistance and point defect model (PDM) to study the passive film characteristics and depassivation mechanism of carbon steel. The experimental results show that the passive film quality and aggressive ions threshold of carbon steel in highly alkaline solutions are mainly related to $\mathrm{pH}$. In the characteristics of the passive film, the correlation between the resistance and the chloride threshold is relatively large. In addition, PDM was used to study the depassivation mechanism of carbon steel. This study demonstrates the effectiveness of PDM for passivation and depassivation of carbon steel in highly alkaline solutions.
\end{abstract}

Keywords: carbon steel, passive film, chloride threshold, depassivation, PDM

\section{$\underline{\text { FULL TEXT }}$}

(C) 2020 The Authors. Published by ESG (www.electrochemsci.org). This article is an open access article distributed under the terms and conditions of the Creative Commons Attribution license (http://creativecommons.org/licenses/by/4.0/). 